\title{
1 A framework for assessing the skill and value of operational recruitment
}

\section{2 forecasts}

3 Christian Kiaer*, Stefan Neuenfeldt and Mark R. Payne

$4 \quad$ *Corresponding Author (E-mail: cmrki@aqua.dtu.dk)

5 Address: Section for Oceans and Arctic, National Institute of Aquatic Resources (DTU Aqua), Technical

6 University of Denmark, Kemitorvet B201, 2800 Kongens Lyngby

7 Keywords: recruitment forecasting, ecological forecasting, predictive skill, forecast value

8 Running header: Skill \& value in recruitment forecasting 


\section{Abstract}

11 Forecasting variation in the recruitment to fish stocks is one of the most challenging and long-running

12 problems in fisheries science and essentially remains unsolved today. Traditionally recruitment forecasts

13 are developed and evaluated based on explanatory and goodness-of-fit approaches that do not reflect

14 their ability to predict beyond the data on which they were developed. Here we propose a new generic

15 framework that allows the skill and value of recruitment forecasts to be assessed in a manner that is

16 relevant to their potential use in an operational setting. We assess forecast skill based on predictive power

17 using a retrospective forecasting approach inspired by meterology, and emphasise the importance of

18 assessing these forecasts relative to a baseline. We quantify the value of these forecasts using an

19 economic cost-loss decision model that is directly relevant to many forecast users. We demonstrate this

20 framework using four stocks of lesser sandeel (Ammodytes marinus) in the North Sea, showing for the

21 first time in an operationally realistic setting that skilful and valuable forecasts are feasible in two of these

22 areas. This result shows the ability to produce valuable short-term recruitment forecasts, and highlights

23 the need to revisit our approach to and understanding of recruitment forecasting. 


\section{Introduction}

25 Recent developments in ocean observations and modelling today make it possible to forecast many of the 26 physical variables in the ocean (Doblas-Reyes et al., 2013; Meehl et al., 2014). Building on top of this data

27 about the ocean environment, forecasts of marine ecological responses have been developed (Payne et al 2017) and provide managers and stakeholders the foresight needed to sustainably manage marine living resources (Tommasi et al., 2017b; Hobday et al., 2018). Examples of operational forecasts already in use include southern Bluefin tuna habitat forecasts (Eveson et al., 2015), the dynamic fisheries bycatch management tool EcoCast (Hazen et al., 2018), and blue whale habitat preference forecast (Hazen et al., 2017). However, these operational fisheries forecast products are currently limited to predictions of distribution and phenology and there are currently no known operational marine fish recruitment forecasts (Payne et al., 2017). fisheries science for the last century (Leggett and Deblois, 1994; Subbey et al., 2014; Tommasi et al., 2017a; Haltuch et al., 2019). Recruitment, the number of young individuals produced each year, has a key role in shaping fish population dynamics (Hilborn and Walters, 1992), especially in determining total allowable catches for short-lived species, where the recruiting year-classes contribute a significant share of the landings. Environmental drivers play an important role in shaping the productivity of such stocks

41 (e.g. via temperature (MacKenzie et al., 2008; Mantzouni and Mackenzie, 2010), salinity (Köster et al.,

42 2005) or phenology (Platt et al., 2003)) and including climate information in stock-assessments can reduce uncertainties in stock status and the risk of over- or under harvesting (Hare et al., 2010; Haltuch and Punt, 2011; Tommasi et al., 2017a, 2017b). The ability to foresee changes in productivity on a short time-scale can therefore enable adaptive and pre-emptive decision-making strategies, benefiting both stakeholders 
Common approaches have however shown limited ability to produce reliable recruitment forecasts for operational (i.e. regularly repeated) use in management. The large variety of underlying environmental, physical and ecosystem processes affecting recruitment simultaneously (Leggett and Deblois, 1994; correlations (Sugihara et al., 2012). Fish population time series are often relatively short in length (Ricard et al., 2012) and hampered by high observation noise, limiting the ability to develop and test predictive models (Clark and Bjørnstad, 2004; Ward et al., 2014). Furthermore, environment-recruitment correlations have been shown to breakdown when confronted with new data, diminishing the uses for management (Myers, 1998; Tommasi et al., 2017b). The relative importance of drivers of recruitment can also change from year to year ("non-stationarity") (Subbey et al., 2014; Haltuch et al., 2019). As a consequence of all of these processes, recruitment forecasts are widely viewed with scepticism in the community today.

Nevertheless, the potential of such forecasts to benefit all those that depend on living marine resources is clear. So how can this potential be realised? And even more importantly, how would we know when we have produced forecasts that can be used as a regular part of decision-making? To answer this question,

62 here we take inspiration from other forecasting fields, and in particular from meteorology, a discipline that has also been attempting to predict chaotic and difficult to observe systems for nearly a century (albeit with considerably more success!). In particular, the question of "what makes a good forecast?" is addressed in a seminal 1993 paper in the field by Alan Murphy (Murphy, 1993) that introduces two key relevant concepts, skill, and value, which form the basis for this work.

67 Murphy defines forecast "skill" as the quantitative ability of the forecast: is it numerically correct? In the marine setting, model performance is often measured based on goodness-of-fit measures that quantify the ability to explain the data e.g (Lindegren et al., 2018). There is however, a fundamental difference 
71 hypotheses, models with high explanatory power cannot be expected to predict well (Levins, 1966;

72 Shmueli, 2009; Dickey-Collas et al., 2014). But when the goal is to produce forecasts to be used regularly

73 to predict into the future for use in a decision-making context, we clearly need to evaluate their predictive

74 power. In the atmospheric and climate sciences for example, skill is often assessed based on retrospective

75 forecast analysis (Wilks, 2011) i.e. predicting beyond the period over which the model was developed or

76 tuned, directly reflecting the way the forecast would be used operationally. Furthermore, meteorology

77 always places its forecasts in the context of a baseline or reference forecast (Jolliffe and Stephenson, 2012;

78 Payne et al., 2012). Common baseline forecasts includes random selection of categories or using the

79 average over a given reference time period, often referred to as climatology in atmospheric sciences

80 (Jolliffe and Stephenson, 2012).

81 Secondly, Murphy discusses the usefulness of a forecast in terms of its "value" in aiding decision-making.

82 A good forecast is of value to an end-user by assisting in decision-making, providing economic value or otherwise benefiting the user (Murphy, 1993). While value in recruitment forecasts has been discussed

84 (e.g. Walters, 1989; Field et al., 2010), a quantitative approach to value is rarely seen in marine science.

85 Simple economic decision models can analyse forecasts under simplified assumptions, helping end-users decide if it is economically wise to follow the forecast (Murphy, 1976a). Quantitatively providing a value

87 assessment can help integrate forecast products directly into a user's framework, allowing users to assess the benefits of a given forecast system and can give a clear insight into how, and when, a forecast should be used (Murphy, 1976a).

Here we argue that as the recruitment problem has never been evaluated from this perspective before, we currently do not know whether it is possible to regularly make skilful and valuable forecasts of recruitment. We therefore combine the ideas Murphy (1993) with the state of the art in recruitment modelling to give a generic framework for developing and assessing short-term recruitment forecasts for 
performance, using validation techniques currently used in atmospheric and meteorological sciences and cost-loss decision model, providing insight into the actual monetary value of the forecast product. We demonstrate the framework using multiple stocks of the ecologically and economically important lesser sandeel (Ammodytes marinus) in the North Sea, where previous studies of recruitment have already highlighted several recruitment correlates (Arnott and Ruxton, 2002; van Deurs et al., 2009; Lindegren et al., 2018).

\section{Methods}

\section{Recruitment forecast framework}

This work presents a generic framework (Figure 1a) for assessing recruitment forecasts of fish stocks in an adapted from the atmospheric sciences, in which the time series of interest is split into two continuous blocks either side of a hypothetical "forecast issue date". The first block is used to parameterise and train data (the "verification" block) based on this model. The issue date is then shifted forward by one time

110 step, the data repartitioned and the process repeated. Iterating over all issue dates, a database of predictions is generated, with each prediction being characterised by the id of the cohort being predicted

112 and issue date: the difference between these two is the "lead time" of the forecast (Figure 1b). The

113 ensemble of predictions can then be compared against the "true" recruitment to that cohort, with various

114 skill metrics being calculated as a function of forecast lead time. The skill metrics generated are then used

115 as the basis for forecast value assessment.

116 There are several key features of this framework that make it highly appropriate for addressing the 117 question at hand i.e. assessing operational forecast skill. The emphasis on temporal blocks, for example, 
differs from other cross-validation approaches (of which it is a subset (Roberts et al., 2017)) and is important as it directly mimics the way in which recruitment forecasts would be used in an operational setting. Furthermore more, temporal blocks also remove the potential for the leakage of information

121 between randomly-selected cross-validation folds, a particularly important issue where there is temporal

122 structure and autocorrelation in the the time series (as is common in recruitment data). This retrospective

123 forecasting approach therefore gives a much more realistic assessment of the skill of forecast, and has

124 been shown to consistently outperform other approaches when forecasting is the goal (Roberts et al.,

125 2017).

126 The user of the temporal-block approach, however, has two key caveats associated with it. Firstly, the

127 choice of the initial forecast issue date separating the training and verification blocks represents a tradeoff

128 between the desire to have as many verifications as possible (and thus the most reliable skill evaluation)

129 and the need to have sufficient data to train the model on in the first place. This tradeoff is more restrictive

130 than random cross-validation and will be particularly acute in instances where the length of the time-

131 series is short: in some cases, there may not be sufficient data to make a reliable skill assessment in this

132 manner. The exact choice will depend on the characteristics of the system at hand. Secondly, and even

133 more importantly, care must be taken to avoid inadvertedly introducing circular reasoning through the

134 use of predictors identified by explanatory analyses over the whole time series: such variables will show

135 skill over the length of the time-series for which they were indentified, but this may not extend into the

136 future. Ideally, predictors should be based on either generic reasoning (e.g. stock-recruitment

137 relationships, the match-mismatch hypothesis) or work published prior to the earliest forecast issue date

138 considered. Alternatively, automatic variable and/or model selection procedures can be incorporated into

139 the "fit model" part of the framework to allow the identification of skilful predictors for each forecast

140 issue date. 
141 The generic nature of the framework mans it can be applied widely: each individual application can and 142 should vary depending on the specifics of the system being assessed. The recruitment time series used 143 can be taken from either stock assessment outputs or from a recruitment-index (e.g. from a larval survey).

144 The selection of predictors is flexible but should be informed by the best available biological knowledge 145 about the stock (Dickey-Collas et al., 2014b; Subbey et al., 2014) (previous caveats not withstanding): stock-specific biomass or demographic indicators, environmental data or other biological parameters (e.g. prey and predator concentrations) can be incorporated equally. Any modelling approach that produces predictions can be considered, including classical recruitment models (e.g. Ricker (Ricker, 1954) and Beverton-Holt (Beverton and Holt, 1957)), statistical and data mining approaches (e.g. generalized additive models (GAMs) (Hastie and Tibshirani, 1986), empirical dynamic modelling (EDM) (Sugihara et al., 2012) and classifier models (Fernandes et al., 2015)): ensembles of models can also be considered e.g. combined via multi-model inference (Burnham and Anderson, 2004). Predictions can (and should) be considered in terms of continuous outputs, probability distributions and/or as categories (i.e.. using a division into terciles (high, medium, low) based on historical observations). The choice of skill metrics will

155 be influenced by the nature of the forecast (Jolliffe and Stephenson, 2012) but should include multiple metrics(Stow et al., 2009; Brun et al., 2016). Skill metrics then form the basis for a quantitative value

157 assessment, evaluating the expected economic value of following a given forecast. Furthermore, the 158 framework allows for forecasts of both single stocks or of aggregations of multiple stocks into a single 159 portfolio forecast, as may be relevant for decision-making across wider-scales (e.g. factories processing many different species)

161 We illustrate the use of this framework through a worked example focusing on recruitment forecasts of the lesser sandeel (Ammodytes marinus) in the North Sea below. 
a)

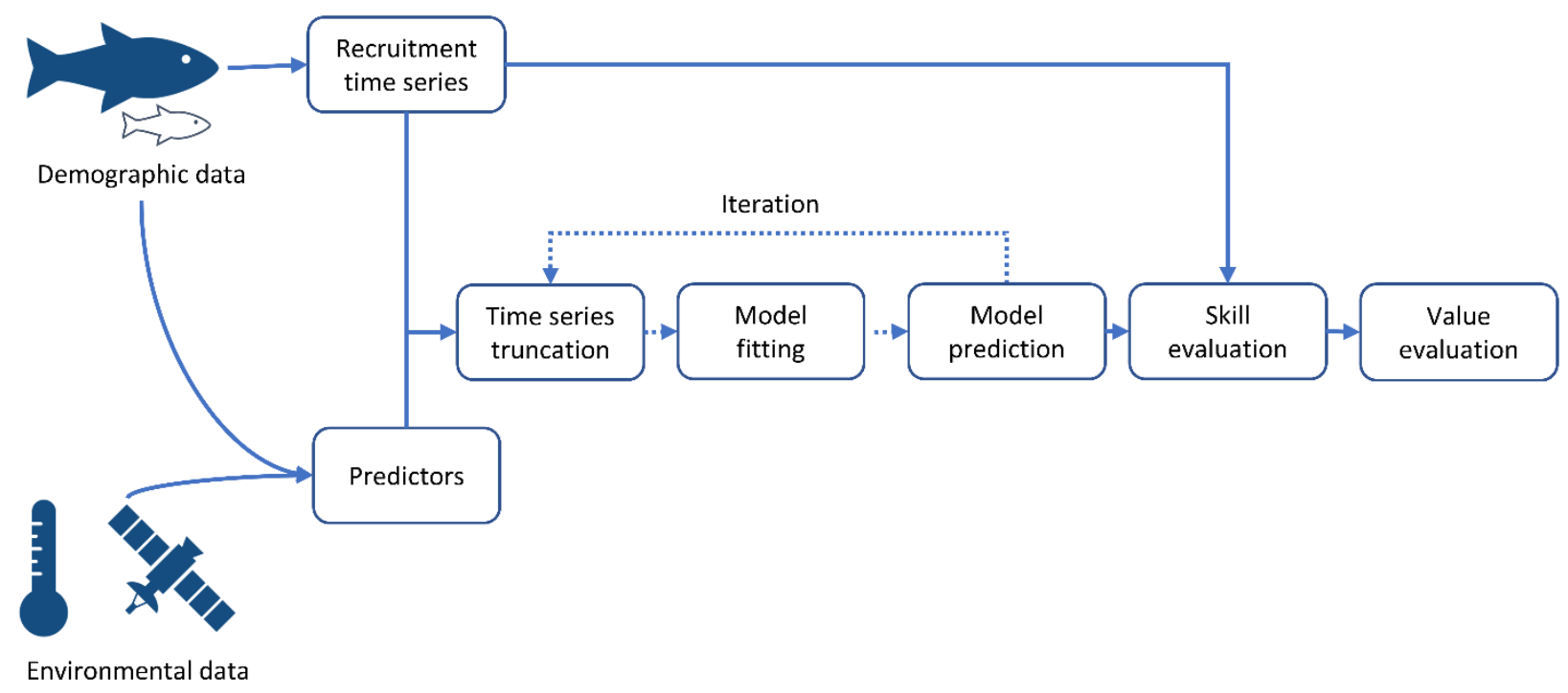

b)

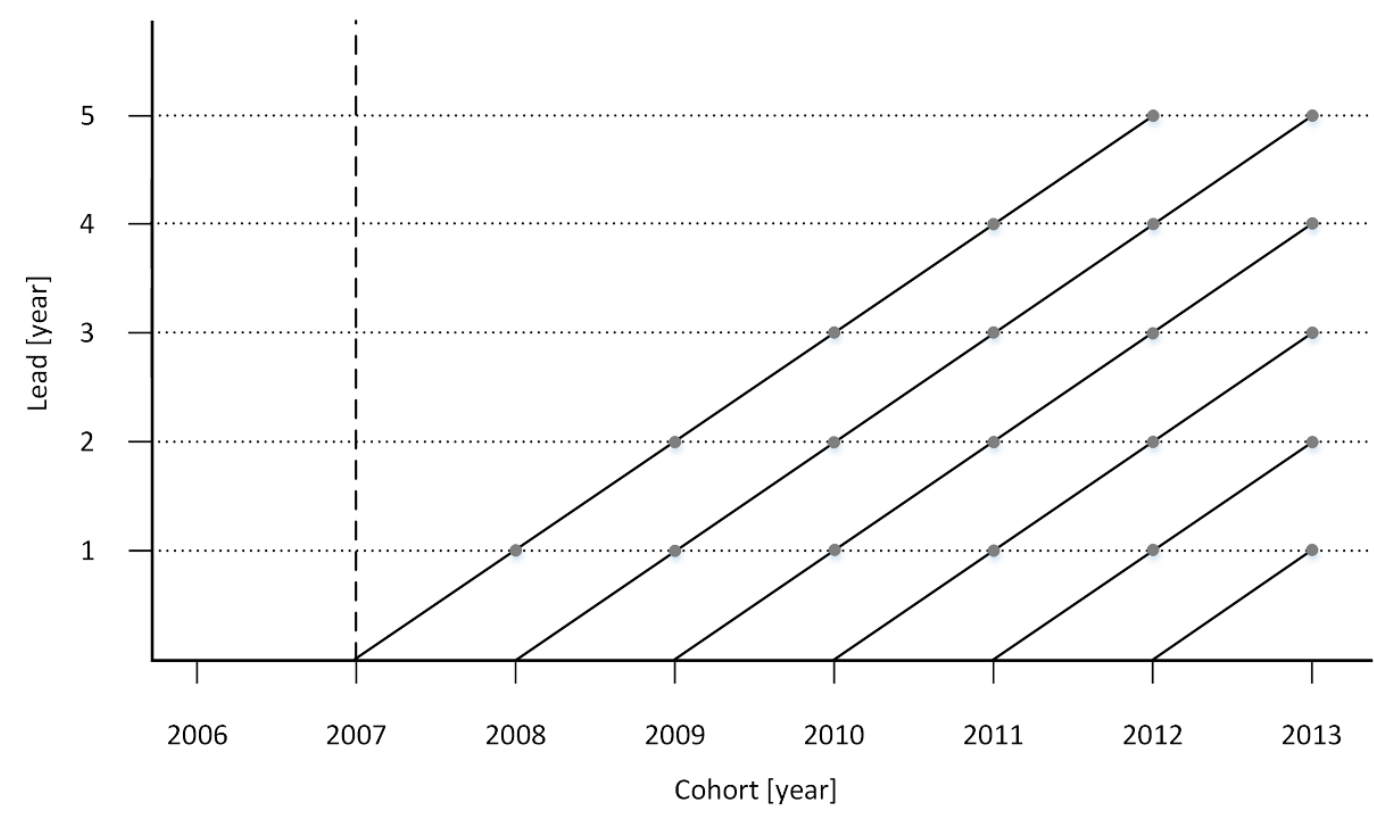

Figure 1 Skill and value assessment framework a) Overview of the process in the forecasting framework. Here, data are extracted and combined into the appropriate modelling data. Afterwards, an iterative process of data truncation and model fitting are the basis of all model objects and predictions. These predictions contains both the current and the retrospective predictions, which can be used for skill and value evaluation b) Schematic of retrospective forecast system used to generate a retrospective forecast time series. One time series is generated at each lead time. Dashed line indicates first data cut-off and the start of the retrospective forecasting period. Dotted lines indicates the forecast time series at a given lead. After the first cut-off each subsequent retrospective forecast will include the previous year's observations increasing the size of the model training data set. For each generated retrospective forecast time series skill, value and accuracy will be evaluated. Depending on species, stocks, data availability and period of interest, the evaluated cohort period and the start of the retrospective analysis can vary. 


\section{Sandeel Case Study}

175 The lesser sandeel is a pelagic species of the Ammodytidea family and is one of the most common

176 sandeels found in the North Sea. Adult lesser sandeel habitats are found in most of the North Sea,

177 generally distributed across shallow sandy banks (van Deurs et al., 2009, Figure 1a). Particle-tracking

178 studies and the sedentary state of post-recruitment sandeel (Christensen et al., 2008; Pedersen et al.,

179 2019) resulted in a division into 7 different individually managed North Sea sandeel stocks. Analytical

180 stock assessments are done in management areas $1 r, 2 r, 3 r$ and 4 (see Figure $2 a$ ), while the remaining

181 three stocks are considered data poor. Sandeel is seen as one of the main links between primary

182 production and the higher trophic levels in the North Sea for both larger piscivorous fish (e.g. cod and

183 haddock) and seabirds (Eliasen et al., 2011). The lesser sandeel has historically supported a large fishery, 184 which has seen a large decline in recent years (Dickey-Collas et al., 2014b). Due to the importance of the 185 species, recruitment to these stocks is well studied (Arnott and Ruxton, 2002; van Deurs et al., 2009;

186 Eigaard et al., 2014; Lindegren et al., 2018). In the south western part of the North Sea (i.e. management

187 area $1 \mathrm{r}$ ), sandeel shows signs of being influenced negatively by temperature, while the abundance of the 188 main prey, Calanus finmarchus, has a positive influence (Arnott and Ruxton, 2002; Lindegren et al.,

189 2018). Density dependence has also been found to be an important driver, where competition with

190 young adults and juveniles has a negative effect on recruitment (van Deurs et al., 2009). Currently, stock

191 assessment uses a geometric mean for recruitment predictions (ICES, 2018). These geometric means will

192 be used as continuous reference models during skill evaluation. 
bioRxiv preprint doi: https://doi.org/10.1101/2021.07.05.451182; this version posted July 9, 2021. The copyright holder for this preprint (which was not certified by peer review) is the author/funder, who has granted bioRxiv a license to display the preprint in perpetuity. It is made available under aCC-BY-NC-ND 4.0 International license.
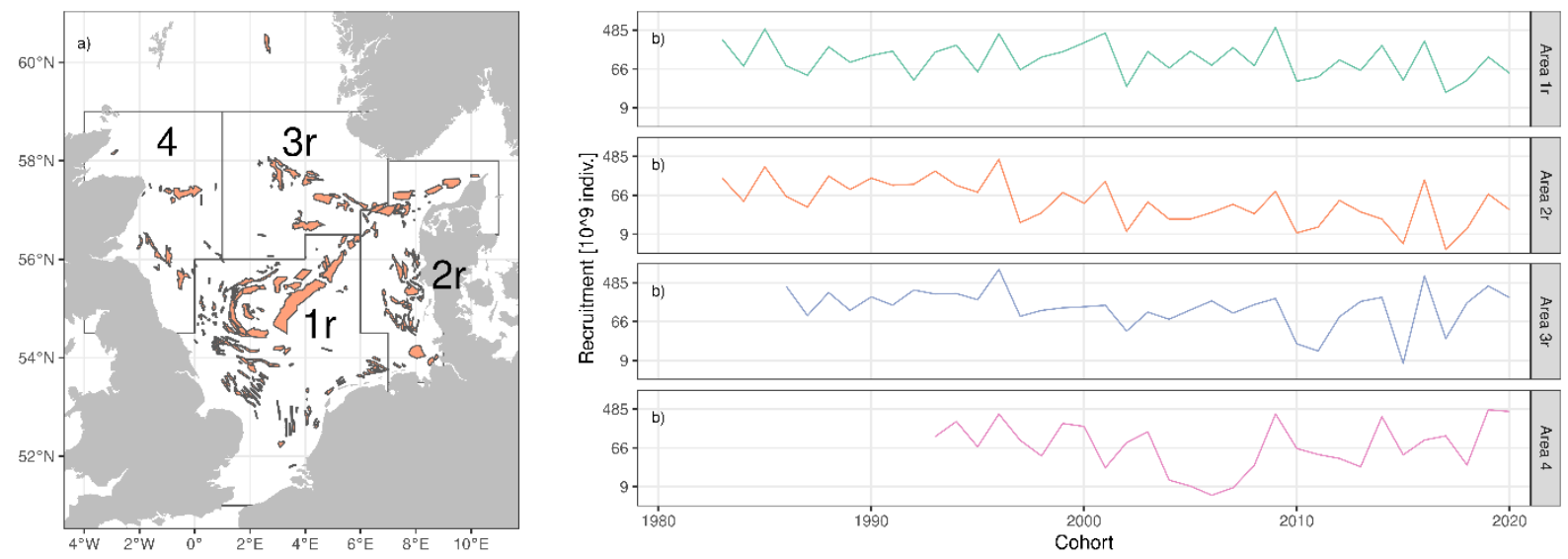

Figure 2 Study area and data a) Map of the North Sea showing the four management areas of sandeel assessed analytically. Sandy habitat banks, the predominant sandeel habitat, are shown in orange. b) Recruitment time series for the four sandeel stocks from the official ICES stock assessment. Dashedhorizontal lines mark the delineation of the upper and lower terciles for each stock. 


\section{Data}

199 Operational forecasts require data to be available at the time of the forecast, potentially excluding some potentially relevant predictors. For example, estimates of zooplankton prey, Calanus finmarchicus and

Temora longicornis have been used in other explanatory studies (Arnott and Ruxton, 2002; van Deurs et al., 2009; Lindegren et al., 2018) but are only available with 1-2 years delay, and are therefore of limited value in forecasting recruitment in this stock in an operational setting. We focus our analyses on data that are available with a maximum of a few months delay. An overview of the data employed is provided in Table 1 and the complete time series are found in Figure S1.

\section{Assessment data}

207 Assessment data used for sandeel modelling is obtained from official ICES advice, based on the stochastic multi-species assessment model, SMS (Pedersen et al., 1999).The SMS model is run in a single-stock mode for sandeel assessments, and integrates data on catches, catch effort, maturity, weight, fishing mortality and natural mortality at a given age (ICES, 2018). All stock assessment data are the current (2021) assessments provided by ICES for area $1 r, 2 r, 3 r$ and 4 (Figure $2 b$ ), where recruits are treated at age 0 . From the assessment data, 4 demographic variables are extracted, consisting of spawning stock biomass

213 (SSB), total stock biomass (TSB), number of individuals (SumN) and number of one-year olds (N1). This

214 allows for different types of interactions between the demography, including density dependence and 215 SSB impact on recruitment. All demographic data are log-transformed before use in modelling and 216 converted to log-anomalies (relative to the average log-value over the full time series for each stock).

\section{Environmental data}

218 High resolution spatial sea surface temperature data is gathered from the Optimum Interpolation Sea

219 Surface Temperature (OISST) product (Banzon et al., 2016). The product is a $0.25^{\circ} \times 0.25^{\circ}$ global daily sea surface temperature (SST) data set on a regular grid. Noting that adult sandeel are bound to specific banks 
221 (Christensen et al., 2008), we produced daily average temperatures over the banks in each stock area, and

222 then averaged temporally over quarters as follows: P3 and P4 represents the temperature anomalies

223 experienced by the adult sandeel from July to December before and during spawning (i.e. the

224 temperatures experienced by the spawners just before spawning). Q1, Q2, Q3 and Q4 are SST anomalies

225 experienced during the egg, larval and juvenile stages from January to December for a given cohort. All

226 extracted temperatures were converted to anomalies from the average (climatology) over the complete

227 SST time series period (1983 to 2020) prior to use in modelling.

\section{Models}

229 Here we use generalised additive models (GAM) as the basis for generating predictions, with model

230 variable selection based on a multi-model inference approach. An advantage of the GAM approach is it's

231 semi-parametric nature that allows for arbitrary but smooth responses. We exploited this feature to

232 incorporated a cohort-based time-varying smoother to allow for changes in the underlying productivity

233 (e.g. due to unquantified variables). This approach allows non-stationarity and systematic shifts in

234 recruitment patterns that would otherwise not be accounted for. For in-depth model descriptions, see

235 supplementary methods.

236 The total of 11 candidate variables (Table 1) give a total of 2048 possible combinations that could be

237 considered. However, in order to minimize risk of overfitting due to both collinearity between model

238 parameters and the short time-series, predictors are split into three groups (as shown in Table 1) based

239 on an exploratory analysis of collinearity (i.e. environmental, demographic and other predictors).

240 Models in the ensemble that incorporated more than one variable in a given group were excluded,

241 giving a total of 819 candidate model structures to be considered.

242 Following the retrospective-forecasting and time-blocking approach proposed in this framework, (Figure

243 1), models were first trained on all data up to a cut-off point and the small-sample Aikaike Information 
244 Criteria (AICC) calculated and converted to model weights (Anderson, 2008). Each model was then used

245 to predict the distribution of expected recruitment values for each cohort in the second, verification

246 block. The individual model posterior predictions were then combined into an ensemble predictive

247 distribution, with the contribution of each model to the ensemble prediction being determined by the

248 AICc weights. Probabilistic categories (i.e. high, medium and low recruitment) and the expected value

249 (mean across the distribution) were then generated from this ensemble predictive distribution. This

250 process was repeated by moving the cut-off point (forecast issue date) forwards by one year, creating a

251 forecast various lead times (Figure 1 b).

252 We evaluated forecast issue dates from 2007-2020, giving a total of 14 forecasts to evaluate: earlier

253 first-forecast dates struck problems with model stability due to the short time series in area 4 (starting

254 from 1993). We focused on the first forecast (one cohort ahead) here, as this is the most relevant to

255 both the management of the stock and to the associated fishing industry. 
Table 1 List of all variables considered and the rationale behind. The parameterisation of each variable in

258 the model is also shown, with $s()$ indicates the use of a spline-smoother and other terms indicating the 259 incorporation of that term as a linear response term.
Variable
Description
Rationale
Parameterisation

\section{Demographic explanatory variables}

\begin{tabular}{llll}
\hline SSB & Spawning stock biomass & $\begin{array}{l}\text { Adult biomass that determines } \\
\text { amount of eggs spawned }\end{array}$ & $\mathrm{s}(\log (\mathrm{SSB}))$ \\
\hline N1 & Number of 1-year olds & $\begin{array}{l}\text { Number of individuals at age } 1 \\
\text { inducing a density dependence }\end{array}$ & $\log (\mathrm{N} 1)$ \\
\hline SumN & Number of individuals & $\begin{array}{l}\text { Entire sandeel population, } \\
\text { inducing density dependence }\end{array}$ & $\log (\mathrm{SumN})$ \\
\hline TSB & Total stock biomass & Combination of all of the above & $\log (\mathrm{TSB})$ \\
\hline
\end{tabular}

\section{Enviromental explanatory variables}

\begin{tabular}{llll}
\hline P3 & Jul-Sep temperatures & $\begin{array}{l}\text { Temperatures experienced by } \\
\text { the adults prior to spawning }\end{array}$ & P3 \\
\hline P4 & Oct-Dec temperatures & $\begin{array}{l}\text { Temperatures experienced by } \\
\text { the adults prior to / during } \\
\text { spawning }\end{array}$ & P4 \\
\hline Q1 & Jan-Mar temperatures & $\begin{array}{l}\text { Temperature experienced during } \\
\text { egg development }\end{array}$ & Q1 \\
\hline Q2 & Apr-Jun temperature & $\begin{array}{l}\text { Temperature experienced by } \\
\text { larvae during pelagic drift phase }\end{array}$ & Q2 \\
\hline Q3 & Jul-Sep temperature & $\begin{array}{l}\text { Temperature experienced by } \\
\text { post-settlement juveniles }\end{array}$ & Q3 \\
& Oct-Dec temperature & $\begin{array}{l}\text { Temperature experienced by } \\
\text { post-settlement juveniles }\end{array}$ & Q4 \\
\hline Q4 & & &
\end{tabular}

\section{Other explanatory variables}

Cohort Cohort year

Included to allow time-variation $\mathrm{s}$ (Cohort)
in the mean productivity of the
stock due to systematic shifts in
other unquantified variables




\section{Skill metrics}

262 Multiple performance metrics are used to assess the retrospective forecasts (Table 2), including both 263 continuous and categorical skill evaluations (Stow et al., 2009; Jolliffe and Stephenson, 2012; Brun et al., 264 2016). Continuous skill uses the mean prediction for a root-mean-square error (RMSE) analysis, giving 265 indications of the accuracy of the forecast. Continuous forecasts can use the mean-squared-error skill 266 score (MSESS) to directly compare the forecast with a reference forecast. The categorical forecasts (high,

267 medium and low) are analysed using the hit rate (H), false alarm rate (F) and true skill score (TSS). Using a 268 combination will quantify both the accuracy of the forecast and forecast performance in each tercile 269 (Murphy, 1969).

270 Reference forecasts were selected according to current stock assessment practices: in this way, it was

271 immediately apparent if the forecast outperforms existing procedures. For the sandeel, the official ICES

272 sandeel advice uses either the 10-years moving geometric mean (Area $2 r$ and 4) or the geometric mean

273 of the full time series (Area $1 r$ and $3 r$ ) (ICES, 2018). These models are selected as reference forecasts in

274 the MSESS. The skill score ranges from negative infinity to 1, effectively comparing the performance gains

275 from using a given forecast compared to the reference. For categorical forecasts, the reference forecast

276 is selected to be random guessing (33\% correct) baseline, both for True Skill Score (TSS) and Ranked 277 Probability Skill Score (RPSS). 
Table 2 Performancel metrics used to evaluate the skill of the forecast system. These values are calculated

a)

\begin{tabular}{l|l|l}
\hline & Observed $\mathrm{P}$ & Observed N \\
\hline Predict P & TP & FP \\
\hline Predict N & FN & TN \\
\hline
\end{tabular}
over all retrospective forecasts at a given lead time. Continuous skill evaluation is also performed for reference forecasts, while the categorical and binary forecast evaluation are only calculated for probabilistic forecasts (Murphy, 1969). MSE contains the mean of the difference between the forecasted $(F)$ and observed $(O)$. The hit rate $(H)$ consists of the proportion of correct forecasts (i.e. true positives (TP) and true negatives $(T N)$ ), while false alarm rate (F) is the proportion of incorrect forecasts (i.e. false positives (FP) and false negatives (FN)).

\begin{tabular}{llcc}
\hline Name of Forecast Quality Measure & Definition & Range & Application \\
\hline Mean square error (MSE) & $\frac{1}{n} \sum_{i=1}^{n}\left(F_{i}-O_{i}\right)$ & {$[0$, inf $]$} & Cont. \\
\hline $\begin{array}{llll}\text { Mean square error skill score } \\
\text { (MSESS) }\end{array}$ & $1-\frac{M S E}{M S E_{\text {reference }}}$ & {$[-$ inf,1] } & Cont. \\
\hline Root-mean-square error (RMSE) & $\sqrt{M S E}$ & {$[0$, inf $]$} & Cont. \\
\hline Proportion correct / Hit rate & $H=\frac{T P+T N}{(T P+T N)+(F P+F N)}$ & {$[0,1]$} & Cat. \\
\hline False alarm rate & $F=\frac{F P+F N}{(T P+T N)+(F P+F N)}$ & {$[0,1]$} & Cat. \\
\hline True Skill Score (TSS) & $T S S=H-F$ & {$[-1,1]$} & Cat. \\
\hline
\end{tabular}

Table 3 a) Confusion matrix generated from the retrospective forecasts at a given lead. Constructed from the sum of observed positives (event occurred) and observed negatives (event didn't occur) with corresponding predicted positives (predict event occurred) and predictive negatives (predicted event not to occur). This results in a matrix of true positive (TP), false positives (FP), false negatives (FN) and true negatives (TN). For recruitment predictions, a TP is when the forecasting system correctly predicts the observed tercile, while a FP is when the system predicts a given tercile, which is not observed. For negative events this is reversed, i.e. FN the tercile is observed while the forecast system doesn't predict it and TN is when the tercile is not observed and the system doesn't predict it. b) Cost matrix used to calculate the value of the forecast system. Here a cost $(C)$ is associated with a precaution and a loss is associated with not taking the precaution and the event occurring.

b)

Cost matrix

\begin{tabular}{l|l|l}
\hline & Event occurs & $\begin{array}{l}\text { Event does not } \\
\text { occur }\end{array}$ \\
\hline $\begin{array}{l}\text { Precaution } \\
\text { taken }\end{array}$ & C & C \\
\hline $\begin{array}{l}\text { Precaution } \\
\text { not taken }\end{array}$ & L & 0 \\
\hline
\end{tabular}




\section{Forecast value}

299 We assess the value of the forecasts using a Richardson cost-loss decision model (Richardson, 2000).

300 Simple economic models, as used here, are widely used in the climate services sector (Pope et al., 2019)

301 to quantify value of e.g. seasonal forecast systems, and provide an intuitive metric for users (Murphy,

302 1976b). Briefly, the model considers the economic impacts of a particular event that is being forecast

303 (e.g. poor recruitment), and the loss (L) that the user could potentially incur. However, the user also has

the ability to avert these losses by implementing precautionary mitigation actions (e.g. based on a

forecast), but doing so also incurs a cost (C) (e.g. mothballing processing plants). These two dimensions

( $\left.E_{\text {reference }}\right)$ followed. The value $(\mathrm{V})$ of the realised forecast system can then be calculated relative to a

perfect forecast system as :

$$
V=\frac{E_{\text {reference }}-E_{\text {forecast }}}{E_{\text {reference }}-E_{\text {perfect }}}
$$

The value of the forecast system, $\mathrm{V}$, is expressed as a non-dimensional number less than 1 and varies as a

314 function of the cost-loss ratio (C/L) of a given user (Richardson, 2000, see eq. 1).

We necessarily extend this analysis to account for the (relatively) small sample size associated with our

316 set of retrospective forecasts and therefore estimate the uncertainties in the value. We model the

317 retrospective contingency table (Table 3a) using a Bayesian multinomial model implemented in Stan

318 (Stan Development Team, 2020) to estimate the vector of true probabilities $\boldsymbol{p}=\left\{p_{T P}, p_{F P}, p_{F N}, p_{T N}\right\}$ of

319 each quadrant of the contingency table. The posterior predictive distribution of $\boldsymbol{p}$ was then sampled 
4000 times and used to construct a corresponding large set of contingency tables and therefore the

321 statistical distribution of the forecast system value, $\mathrm{V}$.

\section{Results}

323 Assessment of the predictions is presented at a forecast lead of one cohort beyond the final year of the

324 assessment, mimicking potential operational usage in these stocks. We find that the stocks in area $1 \mathrm{r}$ and

$3252 r$ have the highest continuous forecast accuracy, while areas $3 r$ and 4 show higher RMSEs (Figure 3a):

326 this dichotomy closely parallels the lengths of the time series of each area (areas $3 r$ and 4 being

327 appreciably shorter) and we hypothesis that the reduced amount of training data may limit the forecast

328 skill. Furthermore, the assessment of area $1 r$ is widely perceived as being the most reliable of the four:

329 the poor performance in areas 3 and 4 in particular may be due to the poor quality of the assessment as

330 much as the poor quality of the forecast. The portfolio forecast, on the other hand, has the highest overall

331 accuracy, showing that the aggregation of predictions can lower the RMSE, highlighting the smoothing

332 effect associated with aggregating noisy data sets.

333 Comparing our forecasts against the existing models used in the assessment of this stock (geometric

334 mean) places their skill in context. In management area $1 r$, the continuous forecast accuracy is better than

335 these reference models (Figure 3a), giving a positive mean-squared error skill score (MSESS) (Figure 3b).

336 The performance of Area $2 r$ is on a par with the reference model, while area $3 r$ and 4 both show a negative

337 MSESS at lead 1, indicating that the forecast model ensemble would not be an improvement over the 338 geometric mean reference model when used as a continuous forecast. 

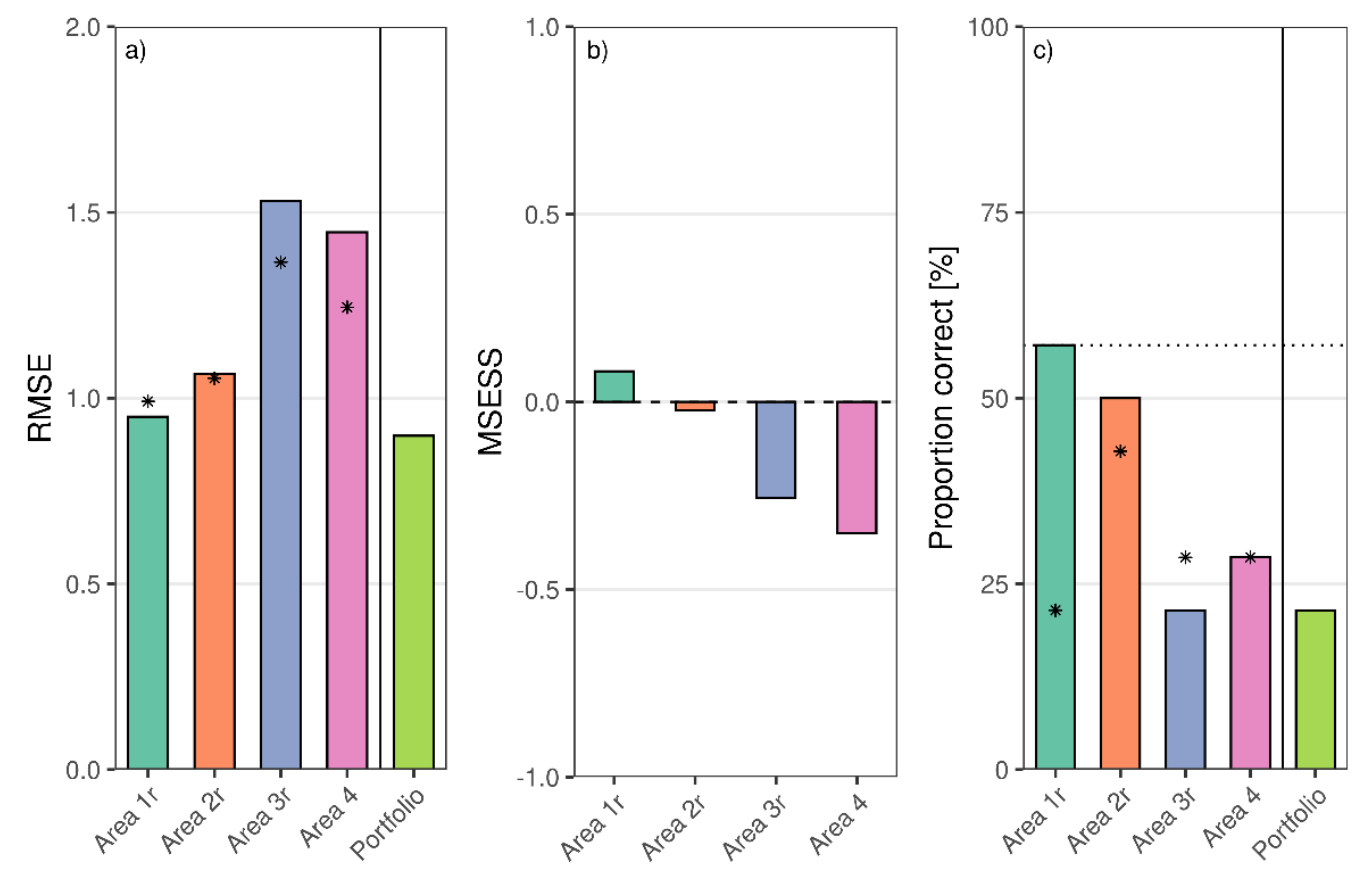

Significance

.... $95 \%$ Signif.

Stock

$\square$ Area $1 \mathrm{r}$

$\square$ Area $2 r$

Area $3 r$

Area 4

Portfolio

Reference model

* Geometric mean

Figure 3 Recruitment forecasts outperform reference forecasts in some cases a) Root-mean-squared error of the different management areas and the portfolio forecast at lead 1. Area $1 r$ and $2 r$ show highest accuracy of individual forecasts, while the portfolio is the overall most accurate, indicating the presence of the portfolio effect. Stars show the reference geometric mean RMSE for the individual management areas. b) Mean-squared error skill score of the individual forecast products for lead 1. Official recruitment prediction model is used as a reference model. Here area $1 r$ and $2 r$ shows better or equal performance to the reference models, while area 3 and 4 has a negative skill score. c) Hit rate of the different management areas indicating the percentage of correct retrospective forecasts at lead 1. Dashed line indicates the $95^{\text {th }}$ percentile level of the random guessing reference forecast. Area $1 \mathrm{r}$ are significantly better than random guessing at 57\% hit rate, while area $2 r$ are borderline significant with $50 \%$ hitrate. Area $3 r$, 4 and the portfolio shows large drop-offs in hit rate with hit rates below 30\%. Stars show the reference geometric mean hit rate. 
bioRxiv preprint doi: https://doi.org/10.1101/2021.07.05.451182; this version posted July 9, 2021. The copyright holder for this preprint (which was not certified by peer review) is the author/funder, who has granted bioRxiv a license to display the preprint in perpetuity. It is made available under aCC-BY-NC-ND 4.0 International license.

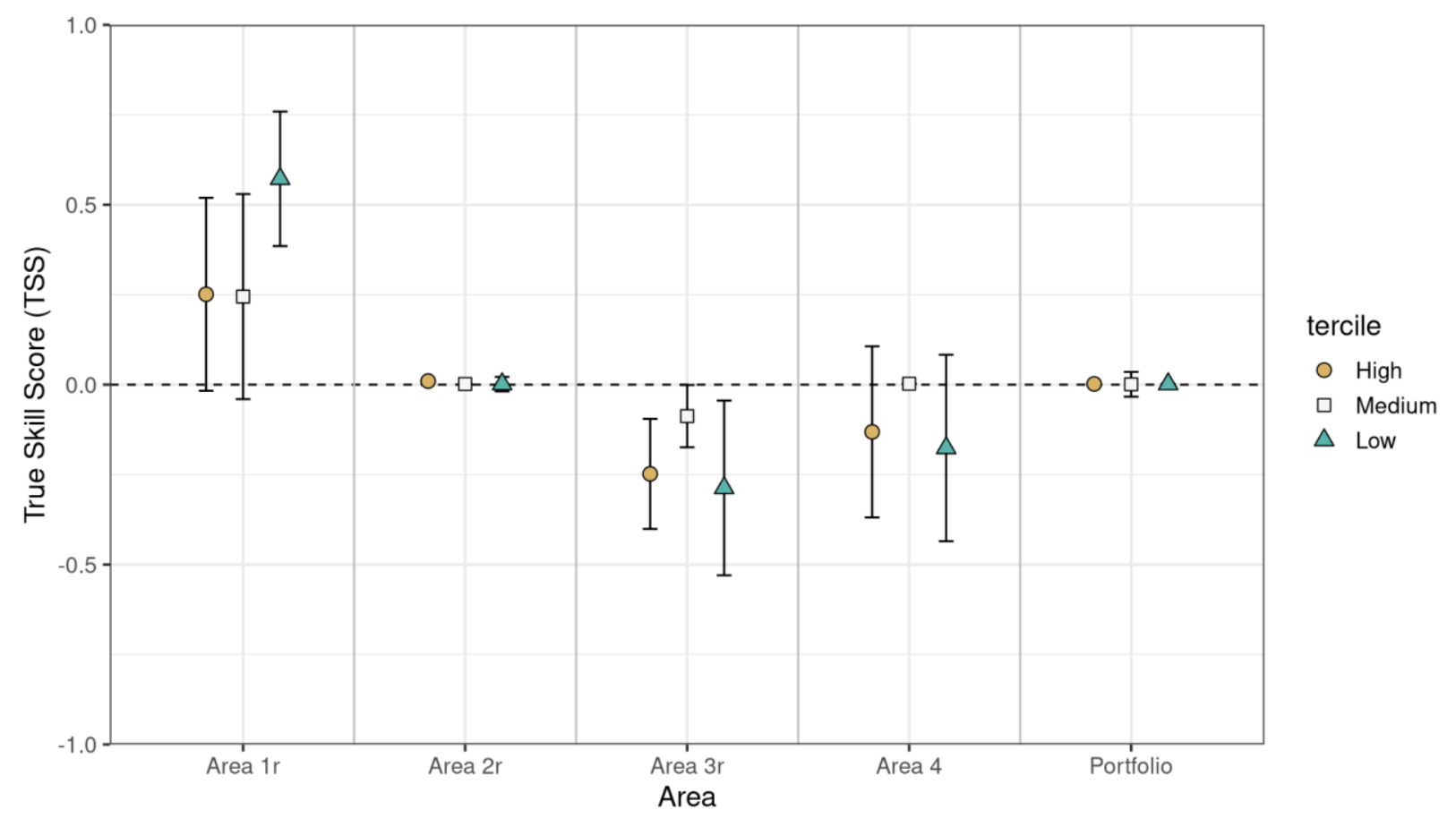

Figure 4 Categorical recruitment forecasts show skill in some areas. Model skill at lead 1 is represented as the True (Peirce) Skill Score (TSS), which ranges between +1 and -1, and has a value of 1 for perfect skill, and 0 for random guessing (black dashed line). Negative values indicates perverse forecast. The 95\% confidence interval for the estimated skill score are shown as error bars on each of the points. Recruitment stocks are shown, with shapes indicating the corresponding recruitment tercile. A positive TSS is seen for all recruitment terciles in area $1 r$, while all other models shows utility close to or worse than random guessing. 
The categorical performance of the forecast models is also broadly similar. Hit rate metrics (how often the system correctly forecasts high, medium or low recruitment) also shows best results in management area 1 , with $57 \%$ correct (Figure 3c), outperforming the outperforming expectd $33 \%$ correct associated with the random guessing of terciles ( $p=0.02$, one-tailed test). Area $2 r$ sees a hit rate of $50 \%$ correct $(p=0.06$, one-tailed test), significant at the $90 \%$ level. A large drop off in hit rate is seen in area $3 r$ and 4 (respectively at $21 \%$ and $28 \%)$, where performance is not significantly better than random guessing $(p=0.74$, and $p=0.52$, one-tailed tests). The portfolio categorical forecast, on the other hand, performs poorly and is not significantly better than random guessing at a $21 \%$ proportion correct ( $p=0.74$, one-tailed test): while aggregating improves the performance of continunous forecasts, it clearly deteriorates categorical forecasts.

371 Further insight into the forecast system can be gained by examining the skill of predicting individual 372 terciles. The true-skill score (TSS) metric combines the specificity (true-positive rate) with the sensitivity 373 (true-negative rate) for a categorical forecast and is applied here to each tercile in turn. The TSS indicates 374 area $1 \mathrm{r}$ being the only management area where the model can reliably differentiate all three categories 375 (Figure 4), consistently outperforming random guessing (i.e. where TSS=0). Most other areas do not show 376 a significant ability to differentiate, either due to the small sample size or poor model skill. For example, 377 area $2 r^{\prime}$ s TSS is not significantly different from zero for all terciles, in part due to the relatively low 378 recruitment seen in the stock in recent years, affecting the ability of the TSS metric to quantify the forecast 379 skill. Areas $3 r$ and 4 have negative or zero skill scores in all categories, likely due to the aforementioned 380 poor quality of these assessments propagating into these forecasts and resulting in a wide prediction distribution. The portfolio forecast shows similar TSS values to area $2 r$, with no categories reaching levels where the system is able to correctly distinguishing between terciles.

383 We assessed the value of the forecast for all areas. The cost-loss decision model for Area $1 r$ (Figure 5) shows positive values in all forecast categories, with especially the low recruitment prediction showing 
385 the highest value over a broad range of cost/loss ratios (Figure 5a). All categories peak at a cost-loss

386 ratio of 0.33 , as is expected from theoretical analyses of this model (Jolliffe and Stephenson, 2012). We

387 account for the small sample size and propagate the uncertainty that it creates into the forecast value

388 by estimating the probability of a positive expected value for a given cost/loss ratio (Figure $5 b$ ): this

389 metric provides decision makers with an indicator when using the forecast will lead to a positive

390 economic return. Here the peak is still seen at a cost-loss ratio of 0.33 , where all categories have above

$39165 \%$ probability of a positive expected long-term value. Following the low recruitment forecast for this

392 cost-loss ratio (i.e. 0.33 ) will result in a $96 \%$ probability of positive value from the forecast, but

393 probabilities above $50 \%$ are also seen across a wide range of cost-loss ratios. While area $2 r, 3 r$ and 4

394 generally can't provide the same levels of value, area $2 r$ could prove valuable when following the high

395 forecast (Figure S3). 
bioRxiv preprint doi: https://doi.org/10.1101/2021.07.05.451182; this version posted July 9, 2021. The copyright holder for this preprint (which was not certified by peer review) is the author/funder, who has granted bioRxiv a license to display the preprint in perpetuity. It is made available under aCC-BY-NC-ND 4.0 International license.
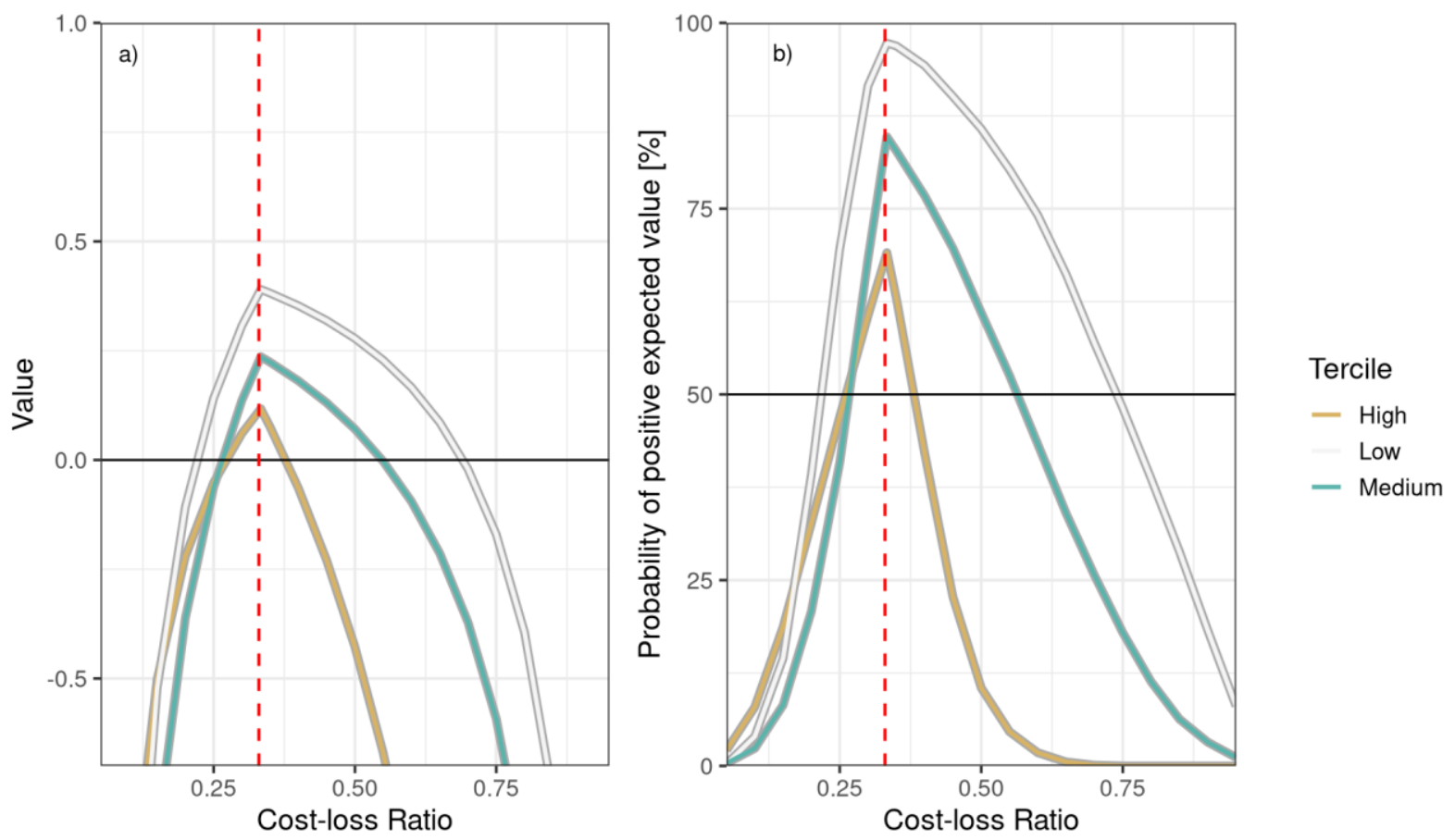

Figure 5 Positive economic value is seen in area 1r recruitment forecasts. Long-term value of a cost-loss decision model in area $1 r$, simulated from a multinomial confusion matrix model. a) Tercile divided value given cost-loss ratios. Solid line indicates zero value. Positive value is seen in all terciles, peaking at a costloss ratio of 0.33 . Most value can be gained by following the low tercile forecast, which corresponds with the highest observed TSS. b) Tercile divided probability of a positive expected value. Calculated from a Bayesian posterior distribution, indicating the probability of drawing a positive value at a given cost-loss ratio. Peak probability is seen at cost-loss ratio of 0.33 , where all terciles shows above $65 \%$ probability of a positive expected value. 


\section{Discussion}

406

407

408

409

410

411

412

413

414

415

416

417

421 2017).

422 While the application of the cost-loss model to estimate forecast value has a clear interpretation in a commercial context, it is less clear how relevant this approach is to fisheries management. Here, cost-loss

424 decision models encapsulate both the costs and losses associated with correctly and incorrectly 425 forecasting recruitment. These ideas can be relevant to fisheries management, as the managers can use this knowledge as the basis of the forecast evaluation, assigning value on e.g. true positives versus false

Here we present a framework for robustly assessing the skill and value of recruitment predictions in a way that is relevant to their use in an operational setting. The case study that we have examined, for four sandeel stocks in the North Sea, illustrates several important conceptual points that deserve particular attention.

Firstly, we show the importance of assessing a forecast system with multiple metrics. While in-sample performance and explanatory metrics are good for finding correlations (and thereby highlighting possible causality), the assessment of predictive skill is quite different and should primarily be shaped by the needs of the forecast user. For example, we identify an overall high forecast accuracy in area 2 (RMSE in Figure 3), but the ability to distinguish between the two lower terciles is poor (Figure 4). Stock assessors may focus on the MSESS as a criteria for uptake, while industry might be more interested in performance in a specific category (e.g. ability to forecast poor year classes) or long-term economic value. Furthermore, the value of a forecast to users within the same sector (e.g. two different fish processing plants) may differ due to differences in their underlying risk profile (i.e. cost-loss ratio) such that while the forecast system may be advantageous for one user, it may not be of use to another. Understanding the decision-making needs of the user is therefore essential to the production of a good forecast (Murphy, 1993; Payne et al., positives. This allows managers and users to understand how the forecast can be incorporated, and how 
forecasts can and should be used in the management of a given stock. While not an economic gain, the

429 value metric of a forecast can be used to assess and manage stocks sustainably, providing the managers

430 with the tools to properly assess how to incorporate forecasts into decision making.Our demonstration of

431 the framework here is based on the use of recruitment estimates directly from the stock assessment, as

432 is still common in the field. It is nevertheless important to remember that these data are estimates that

433 are also uncertain (Brooks and Deroba, 2015). The framework presented here has the ability, however,

434 incorporate a more robust treatment of such uncertainties. For example, uncertainty estimates (e.g. in

435 recruitment) can be incorporated directly into forecast model if desired. Retrospective biases in the stock

436 assessment incorporated into the model fitting procedure by e.g. fitting the forecast model to stock-

437 assessment outputs based on a model up to 2007 , and then predicting forward in time from there. While

438 such an approach would be idealogically cleaner, it was not possible here due to technical challenges in

439 producing a sufficient number of retrospective assessments for these stocks. A further extension would

440 be to incorporate the recruitment forecast model directly into the stock assessment model, thereby

441 making a seamless assessment and recruitment prediction system. Regardless of the approach, the

442 framework presented can adapt to both the technical limitations of the system being studied, and

443 changing norms in the approach to this issue.

444 Finally, our results for North Sea sandeel show that our understanding of recruitment predictability needs

445 to be re-assessed. Contrary to the wide-spread belief that recruitment can't be forecast, we have shown

446 in a setting that directly mirrors operational useage that skilful and valuable recruitment forecasts can be

447 made. Shifting the way that we assessment recruitment skill from an explanatory to predictive setting

448 greatly increases the confidence in, and transparency of, these results, and paves the way for their direct

449 up-take in decision making. Furthermore, taking the next step of assessing the value of these forecasts

450 gives a more nuanced view that is directly relevant to decision-makers, particularly in the commercial 
sector. These results therefore open the way for a new paradigm in addressing this long-running, but

452 fundamental question in fisheries management.

\section{Acknowledgements}

The research leading to these results has received funding from the European Union's Horizon 2020

research and innovation programme under grant agreement No 727852 (Blue-Action).

This study was co-funded the PANDORA project which received funding from the European Union's

Horizon 2020 research and innovation programme under the grant agreement no. 773713.

\section{Data availability}

The data that support the findings of this study are available from the corresponding author upon

reasonable request.

\section{References}

462

463
Anderson, D. R. 2008. Model Based Inference in the Life Sciences: A Primer on Evidence. Springer New York, New York, NY. 184 pp. http://www.springerlink.com/index/10.1007/978-0-387-74075-1 (Accessed 23 January 2014).

Arnott, S. A., and Ruxton, G. D. 2002. Sandeel recruitment in the North Sea: Demographic, climatic and trophic effects. Marine Ecology Progress Series, 238: 199-210.

Banzon, V., Smith, T. M., Chin, T. M., Liu, C., and Hankins, W. 2016. A long-term record of blended satellite and in situ sea-surface temperature for climate monitoring, modeling and environmental studies. Earth System Science Data, 8: 165-176. https://www.earth-syst-sci-data.net/8/165/2016/.

Brooks, E. N., and Deroba, J. J. 2015. When "data" are not data: The pitfalls of post hoc analyses that use stock assessment model output. Canadian Journal of Fisheries and Aquatic Sciences, 72: 634-641.

Browman, H., Cushing, D., DeBlois, E., Ellertsen, B., Fossum, P., Leggett, W., Myers, R., et al. 1995. Commentaries on current research trends in recruitment studies. Marine Ecology Progress Series, 128: 305-310.

Brun, P., Kiørboe, T., Licandro, P., and Payne, M. R. 2016. The predictive skill of species distribution models for plankton in a changing climate. Global change biology, 22: 3170-3181.

Christensen, A., Jensen, H., Mosegaard, H., St. John, M., and Schrum, C. 2008. Sandeel (Ammodytes marinus) larval transport patterns in the North Sea from an individual-based hydrodynamic egg and larval model. Canadian Journal of Fisheries and Aquatic Sciences, 65: 1498-1511. http://www.nrcresearchpress.com/doi/abs/10.1139/F08-073.

Clark, J. S., and Bjørnstad, O. N. 2004. POPULATION TIME SERIES: PROCESS VARIABILITY, OBSERVATION 
ERRORS, MISSING VALUES, LAGS, AND HIDDEN STATES. Ecology, 85: 3140-3150. http://doi.wiley.com/10.1890/03-0520.

Dickey-Collas, M., Payne, M. R., Trenkel, V. M., and Nash, R. D. M. 2014a. Food for Thought Hazard warning: model misuse ahead. ICES Journal of Marine Science, 71: 2300-2306. http://icesjms.oxfordjournals.org/content/early/2014/01/09/icesjms.fst215.short.

Dickey-Collas, M., Engelhard, G. H., Rindorf, A., Raab, K., Smout, S., Aarts, G., van Deurs, M., et al. 2014b. Ecosystem-based management objectives for the North Sea: riding the forage fish rollercoaster. ICES Journal of Marine Science, 71: 128-142. https://academic.oup.com/icesjms/article/71/1/128/642315.

Doblas-Reyes, F. J., García-Serrano, J., Lienert, F., Biescas, A. P., and Rodrigues, L. R. L. 2013. Seasonal climate predictability and forecasting: Status and prospects. Wiley Interdisciplinary Reviews: Climate Change, 4: 245-268.

Eigaard, O. R., van Deurs, M., Behrens, J. W., Bekkevold, D., Brander, K., Plambech, M., Plet-Hansen, K. S., et al. 2014. Prey or predator - Expanding the food web role of sandeel Ammodytes marinus. Marine Ecology Progress Series, 516: 267-273.

Eliasen, K., Reinert, J., Gaard, E., Hansen, B., Jacobsen, J. A., Grønkjær, P., and Christensen, J. T. 2011. Sandeel as a link between primary production and higher trophic levels on the Faroe shelf. Marine Ecology Progress Series, 438: 185-194.

Eveson, J. P., Hobday, A. J., Hartog, J. R., Spillman, C. M., and Rough, K. M. 2015. Seasonal forecasting of tuna habitat in the Great Australian Bight. Fisheries Research, 170: 39-49. Elsevier B.V. http://dx.doi.org/10.1016/j.fishres.2015.05.008.

Field, J. C., MacCall, A. D., Ralston, S., Love, M. S., and Miller, E. F. 2010. Bocaccionomics: The effectiveness of pre-recruit indices for assessment and management of bocaccio. California Cooperative Oceanic Fisheries Investigations Reports, 51: 77-90.

Haltuch, M. A., and Punt, A. E. 2011. The promises and pitfalls of including decadalscale climate forcing of recruitment in groundfish stock assessment. Canadian Journal of Fisheries and Aquatic Sciences, 68: 912-926.

Haltuch, M. A., Brooks, E. N., Brodziak, J., Devine, J. A., Johnson, K. F., Klibansky, N., Nash, R. D. M., et al. 2019. Unraveling the recruitment problem: A review of environmentally-informed forecasting and management strategy evaluation. Fisheries Research, 217: 198-216. Elsevier. https://doi.org/10.1016/j.fishres.2018.12.016.

Hare, J. A., Alexander, M. A., Fooarty, M. J., Williams, E. H., and Scott, J. D. 2010. Forecasting the dynamics of a coastal fishery species using a coupled climate - Population model. Ecological Applications, 20: 452-464.

Hazen, E. L., Palacios, D. M., Forney, K. A., Howell, E. A., Becker, E., Hoover, A. L., Irvine, L., et al. 2017. WhaleWatch : a dynamic management tool for predicting blue whale density in the California Current: $1415-1428$.

Hazen, E. L., Scales, K. L., Maxwell, S. M., Briscoe, D. K., Welch, H., Bograd, S. J., Bailey, H., et al. 2018. A dynamic ocean management tool to reduce bycatch and support sustainable fisheries. Science Advances, 4: 1-8. 
Hilborn, R., and Walters, C. J. 1992. Quantitative Fisheries Stock Assessment. Springer US, Boston, MA. http://link.springer.com/10.1007/978-1-4615-3598-0.

Hobday, A. J., Spillman, C. M., Eveson, J. P., Hartog, J. R., Zhang, X., and Brodie, S. 2018. A Framework for Combining Seasonal Forecasts and Climate Projections to Aid Risk Management for Fisheries and Aquaculture. Frontiers in Marine Science, 5: 1-9. http://journal.frontiersin.org/article/10.3389/fmars.2018.00137/full.

ICES. 2018. Report of the Herring Assessment Working Group for the Area South of $62^{\circ} \mathrm{N}$ (HAWG). 29-31 January 2018 and 12-20 March 2018. ICES HQ, Copenhagen, Denmark. ICES CM 2018/ACOM:07.

Jolliffe, I. T., and Stephenson, D. B. 2012. Forecast Verification: A Practitioner's Guide in Atmospheric Science. John Wiley \& Sons, Ltd, Chichester, UK. http://doi.wiley.com/10.1002/9781119960003.

Köster, F. W., Möllmann, C., Hinrichsen, H. H., Wieland, K., Tomkiewicz, J., Kraus, G., Voss, R., et al. 2005. Baltic cod recruitment - The impact of climate variability on key processes. ICES Journal of Marine Science, 62: 1408-1425.

Leggett, W. C., and Deblois, E. 1994. Recruitment in marine fishes: Is it regulated by starvation and predation in the egg and larval stages? Netherlands Journal of Sea Research, 32: 119-134.

Levins, R. 1966. Linked references are available on JSTOR for this article : THE STRATEGY OF MODEL BUILDING IN population biology arises. American Scientist, 54: 421-431.

Lindegren, M., van Deurs, M., MacKenzie, B. R., Worsoe Clausen, L., Christensen, A., and Rindorf, A. 2018. Productivity and recovery of forage fish under climate change and fishing: North Sea sandeel as a case study. Fisheries Oceanography, 27: 212-221.

MacKenzie, B. R., Horbowy, J., and Köster, F. W. 2008. Incorporating environmental variability in stock assessment: predicting recruitment, spawner biomass, and landings of sprat (Sprattus sprattus) in the Baltic Sea. Canadian Journal of Fisheries and Aquatic Sciences, 65: 1334-1341. http://article.pubs.nrc-cnrc.gc.ca/ppv/RPViewDoc?issn=1205$7533 \&$ volume $=65 \&$ issue $=7 \&$ startPage $=1334 \& a b=y$.

Mantzouni, I., and Mackenzie, B. R. 2010. Productivity responses of a widespread marine piscivore, Gadus morhua, to oceanic thermal extremes and trends. Proceedings. Biological sciences / The Royal Society, 277: 1867-74. http://www.pubmedcentral.nih.gov/articlerender.fcgi?artid=2871868\&tool=pmcentrez\&rendertyp $\mathrm{e}=$ abstract.

Meehl, G. A., Goddard, L., Boer, G., Burgman, R., Branstator, G., Cassou, C., Corti, S., et al. 2014. Decadal climate prediction an update from the trenches. Bulletin of the American Meteorological Society, 95: 243-267.

Murphy, A. H. 1969. On the "Ranked Probability Score". Journal of Applied Meteorology, 8: 988-989. http://journals.ametsoc.org/doi/abs/10.1175/15200450\%281969\%29008\%3C0988\%3AOTPS\%3E2.0.CO\%3B2.

Murphy, A. H. 1976a. Decision-Making Models in the Cost-Loss Ratio Situation and Measures of the Value of Probability Forecasts. Monthly Weather Review, 104: 1058-1065. http://journals.ametsoc.org/doi/10.1175/1520-0493(1976)104\%3C1058:DMMITC\%3E2.0.CO;2.

Murphy, A. H. 1976b. Decision-Making Models in the Cost-Loss Ratio Situation and Measures of the 
Value of Probability Forecasts. Monthly Weather Review, 104: 1058-1065.

563

564

565

566

567

568

569

570

571

572

573

574

575

576

577

578

579

580

581

582

583

584

585

586

587

588

589

590

591

592

593

594

595

596

597

598

599

600

Murphy, A. H. 1993. What Is a Good Forecast? An Essay on the Nature of Goodness in Weather Forecasting. Weather and Forecasting, 8: 281-293.

Myers, R. A. 1998. When Do Environment-recruitment Correlations Work? Reviews in Fish Biology and Fisheries, 8: 285-305. http://www.springerlink.com/index/P76366G6716KN272.pdf (Accessed 29 March 2011).

Payne, M. R., Egan, A., Fässler, S. M. M., Hátún, H., Holst, J. C., Jacobsen, J. A., Slotte, A., et al. 2012. The rise and fall of the NE Atlantic blue whiting (Micromesistius poutassou). Marine Biology Research, 8: 475-487.

Payne, M. R., Hobday, A. J., MacKenzie, B. R., Tommasi, D., Dempsey, D. P., Fässler, S. M. M., Haynie, A. C., et al. 2017. Lessons from the First Generation of Marine Ecological Forecast Products. Frontiers in Marine Science, 4. http://journal.frontiersin.org/article/10.3389/fmars.2017.00289/full.

Pedersen, E. J., Miller, D. L., Simpson, G. L., and Ross, N. 2019. Hierarchical generalized additive models in ecology: an introduction with mgcv. PeerJ, 7: e6876.

Pedersen, S. A., Lewy, P., and Wright, P. 1999. Assessments of the lesser sandeel (Ammodytes marinus) in the North Sea based on revised stock divisions. Fisheries Research, 41: 221-241. https://linkinghub.elsevier.com/retrieve/pii/S0165783699000260.

Platt, T., Fuentes-Yaco, C., and Frank, K. T. 2003. Spring algal bloom and larval fish survival off Nova Scotia. Nature, 423: 398-399.

Pope, E. C. D., Buontempo, C., and Economou, T. 2019. Exploring constraints on the realised value of a forecast-based climate service. Climate Services, 15: 100102. Elsevier. https://doi.org/10.1016/j.cliser.2019.100102.

Ricard, D., Minto, C., Jensen, O. P., and Baum, J. K. 2012. Examining the knowledge base and status of commercially exploited marine species with the RAM Legacy Stock Assessment Database. Fish and Fisheries, 13: 380-398.

Richardson, D. S. 2000. Skill and relative economic value of the ECMWF ensemble prediction system. Quarterly Journal of the Royal Meteorological Society, 126: 649-667. http://doi.wiley.com/10.1002/qj.49712656313.

Roberts, D. R., Bahn, V., Ciuti, S., Boyce, M. S., Elith, J., Guillera-Arroita, G., Hauenstein, S., et al. 2017. Cross-validation strategies for data with temporal, spatial, hierarchical, or phylogenetic structure. Ecography, 40: 913-929.

Shmueli, G. 2009. To Explain or To Predict? Ssrn, 25: 289-310.

Stan Development Team. 2020. Stan Modeling Language Users Guide and Reference Manual, 2.19.0.

Stow, C. A., Jolliff, J., McGillicuddy, D. J., Doney, S. C., Allen, J. I., Friedrichs, M. A. M., Rose, K. A., et al. 2009. Skill assessment for coupled biological/physical models of marine systems. Journal of Marine Systems, 76: 4-15. Elsevier B.V. http://dx.doi.org/10.1016/j.jmarsys.2008.03.011.

Subbey, S., Devine, J. A., Schaarschmidt, U., and Nash, R. D. M. 2014. Modelling and forecasting stockrecruitment: current and future perspectives. ICES Journal of Marine Science, 71: 2307-2322. https://academic.oup.com/icesjms/article/71/8/2307/2804451. 
601

602

603

604

605

606

607

608

609

610

611

612

613

614

615

616

617

618

619

620
Sugihara, G., May, R., Ye, H., Hsieh, C. -h., Deyle, E., Fogarty, M., and Munch, S. 2012. Detecting Causality in Complex Ecosystems. Science, 338: 496-500.

http://www.sciencemag.org/cgi/doi/10.1126/science.1227079.

Tommasi, D., Stock, C. A., Pegion, K., Vecchi, G. A., Methot, R. D., Alexander, M. A., and Checkley, D. M. 2017a. Improved management of small pelagic fisheries through seasonal climate prediction: Ecological Applications, 27: 378-388.

Tommasi, D., Stock, C. A., Hobday, A. J., Methot, R., Kaplan, I. C., Eveson, J. P., Holsman, K., et al. 2017b. Managing living marine resources in a dynamic environment: The role of seasonal to decadal climate forecasts. Progress in Oceanography, 152: 15-49. http://linkinghub.elsevier.com/retrieve/pii/S0079661116301586.

van Deurs, M., Van Hal, R., Tomczak, M. T., and Jónasdóttir, S. H. 2009. Recruitment of lesser sandeel Ammodytes marinus in relation to density dependence and zooplankton composition. Marine Ecology Progress Series, 381: 249-258.

Walters, C. J. 1989. Value of Short-Term Forecasts of Recruitment Variation for Harvest Management.

Ward, E. J., Holmes, E. E., Thorson, J. T., and Collen, B. 2014. Complexity is costly: A meta-analysis of parametric and non-parametric methods for short-term population forecasting. Oikos, 123: 652661.

Wilks, D. 2011. Statistical Methods in the Atmospheric Sciences. 704 pp. https://linkinghub.elsevier.com/retrieve/pii/B9780123850225000014. 